\title{
Surgical management of aneurysms of arteriovenous fistulae in hemodialysis patients: A case series
}

This article was published in the following Dove Press journal:

Open Access Surgery

27 March 2010

Number of times this article has been viewed

\author{
Christopher SP Valentine \\ Olugbenga Aworanti \\ Department of Surgery, Cornwall \\ Regional Hospital, Montego Bay, \\ Jamaica
}

Background: One of the complications of arteriovenous (AV) fistulae used for hemodialysis is aneurysm formation and subsequent risk for rupture. Surgery is one of the modalities utilised to treat this condition.

Methods: A retrospective review of medical records was done to identify patients managed surgically at our institution over a four-year period. The surgical procedures varied from aneurysmectomy alone, to partial aneurysmectomy with preservation of the fistula, to aneurysmectomy and creation of a new fistula.

Results: Seven patients who had undergone AV fistula aneurysm were identified. The usual presentation was of a pulsatile, expansile mass at the site of the AV fistula scar associated with pain. Two patients presented with bleeding. Patients in whom preservation of the fistula was attempted had poor patency of the fistula postoperatively. All patients in whom aneurysmectomy with creation of a new fistula was done had a functional fistula postoperatively.

Discussion: Others have described surgical techniques for fistula preservation, but these have necessitated a significant delay until use of the fistula. Arterial blood flow in a new fistula increases gradually for up to 10 days, then tapers off. Therefore, it should be possible to begin use of the fistula at this time.

Conclusions: AV fistula aneurysms may be treated by aneurysmectomy and creation of a new fistula. This may also reduce the waiting time before the fistula can be used for dialysis.

Keywords: arteriovenous fistula, aneurysm, hemodialysis aneurysm, pseudoaneurysm

\section{Introduction}

Arteriovenous (AV) fistulae are often created to provide access for hemodialysis in chronic renal failure patients. These fistulae are prone to developing their own complications, one of which is the formation of aneurysms which can rupture, resulting in possible hemorrhage. This complication can be dealt with by several techniques, including surgery. Few relevant surgical procedures have been described, but most have attempted to preserve the function of the existing fistula. ${ }^{1-4}$ There seems to be no consensus on the best procedure to reduce the risk of rupture while leaving the patient with a functioning fistula. We present our experience with surgical management of these aneurysms at a small hemodialysis unit and outline our current preferred surgical procedure for treating these patients.

\section{Methods}

A retrospective review of medical records was done at our institution over a period of four years (June 2005 to July 2009) to identify patients diagnosed with and surgically treated for aneurysm of an AV fistula used for hemodialysis access. submit your manuscript | www.dovepress.com

Dovepress
Open Access Surgery 2010:3 9-12

(C) 20IOValentine and Aworanti, publisher and licensee Dove Medical Press Ltd.This is an Open Access article which permits unrestricted noncommercial use, provided the original work is properly cited. 
All procedures were performed under general anesthesia, and preoperative and postoperative care was undertaken with support from the nephrology team. Patients were scheduled for surgery because of risk of rupture or actual rupture, rather than aneurysmal size. The surgical procedures varied over the review period. The first patient had an aneurysmectomy only. This involved excision of the aneurysmal dilatation along with the AV fistula, followed by arterial repair, thereby leaving the patient without a fistula.

Following this, attempts were made to preserve the AV fistula by performing partial excision of the aneurysmal sac with a sutured repair, while leaving the fistula intact. The patency of these fistulae was poor and none of them were usable after the procedure. We then switched to performing aneurysmectomy followed by creation of a new AV fistula in the same artery via the same incision. As part of this procedure the aneurysmal dilatation, including the AV fistula, was excised. If possible, the non-aneurysmal wall of the artery was preserved, along with a sutured repair of the arterial defect (Figure 1b). The involved segment of artery was completely excised if necessary, followed by primary arterial repair. A proximal end-to-side (vein to artery) AV fistula was then constructed.

\section{Results}

Seven patients were identified to have undergone surgery for AV fistula aneurysm during the review period. The patients were all managed by one surgeon $(\mathrm{CV})$ and had a variable duration of followup. There were five females and two males, of age range 25-44 years (see Table 1). Although exact location of the fistula varied from patient to patient, all fistulae were sited in an upper limb. The age of the fistulae ranged from $1.5-5.0$ years. No relationship was found between age of the fistula and presentation with aneurysm. Duration of signs and/or symptoms of aneurysm ranged from a few weeks to approximately one year.

Clinical presentation was of a pulsatile, expansile swelling in the region of the AV fistula scar with associated pain. Diagnosis was always made on clinical features, and the aneurysms ranged in size from $6 \mathrm{~cm}$ to $10 \mathrm{~cm}$ in maximal diameter. All patients were assessed clinically for adequate distal perfusion. Some, but not all, patients proceeded to a

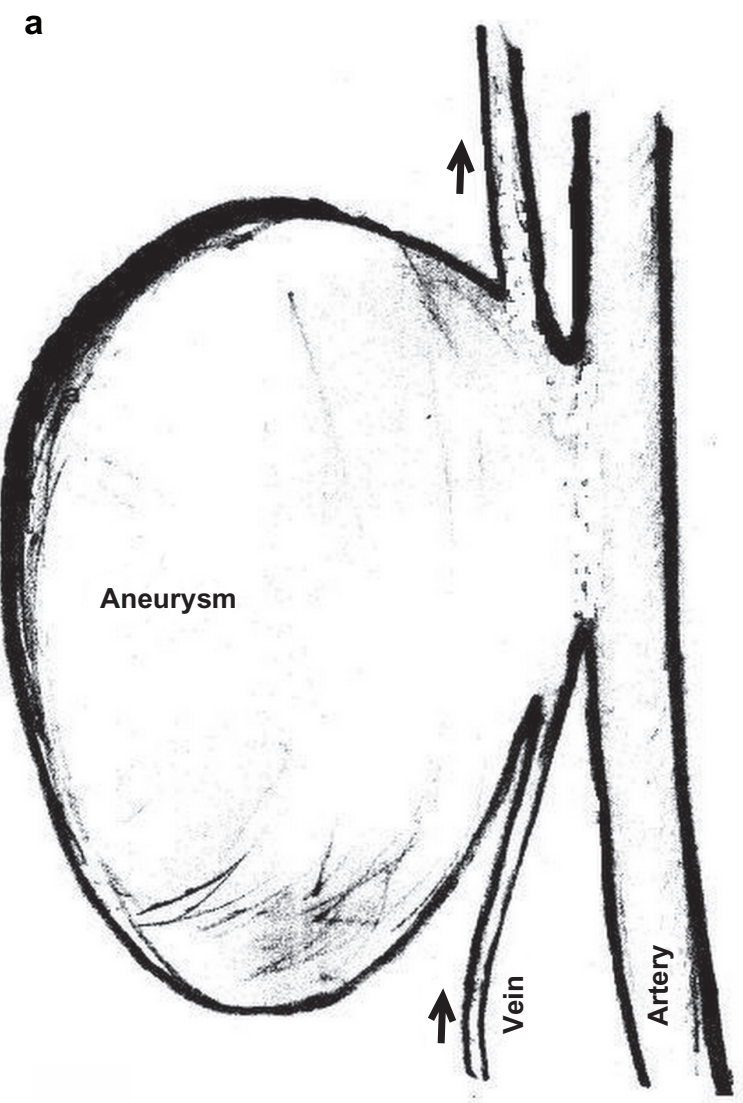

b

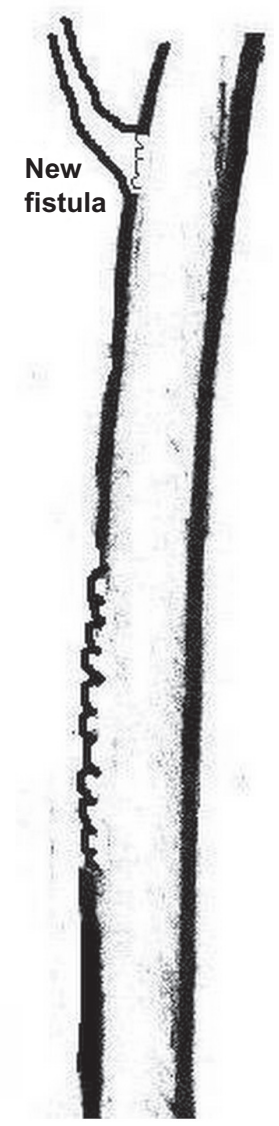

Figure I AV fistula aneurysm repair - a) the aneurysm as was typically found at the fistula site b) after excision and arterial repair with creation of a new fistula. 
Table I Results from surgical procedures

\begin{tabular}{|c|c|c|c|c|c|}
\hline Patient & Age (years) & $\begin{array}{l}\text { Location of } \\
\text { fistula }\end{array}$ & Age of fistula & Procedure & Outcome of fistula \\
\hline I & 35 & Antecubital fossa & 4 years & $\begin{array}{l}\text { Aneurysmectomy with } \\
\text { repair of artery }\end{array}$ & N/A \\
\hline 2 & 40 & Proximal forearm & 3 years & $\begin{array}{l}\text { Partial aneurysmectomy } \\
\text { preserving fistula }\end{array}$ & patent short term \\
\hline 3 & 44 & Distal forearm & NK & $\begin{array}{l}\text { Partial aneurysmectomy } \\
\text { preserving fistula }\end{array}$ & not patent \\
\hline 4 & 33 & Distal arm & 1.5 years & $\begin{array}{l}\text { Aneurysmectomy, repair artery } \\
\text { and creation of new fistula }\end{array}$ & patent \\
\hline 5 & 25 & Distal forearm & I.5 years & $\begin{array}{l}\text { Aneurysmectomy, repair artery } \\
\text { and creation of new fistula }\end{array}$ & patent \\
\hline 6 & 41 & Antecubital fossa & 5 years & $\begin{array}{l}\text { Aneurysmectomy, repair artery } \\
\text { and creation of new fistula }\end{array}$ & patent \\
\hline 7 & 53 & Proximal forearm & 1.5 years & $\begin{array}{l}\text { Aneurysmectomy, repair artery } \\
\text { and creation of new fistula }\end{array}$ & patent \\
\hline
\end{tabular}

Abbreviations: NK, not known; N/A, not applicable.

duplex ultrasound scan which confirmed the clinical diagnosis in all cases. Two patients presented with bleeding from the swollen area around the AV fistula scar. Three patients presented with signs of localised cellulitis, with no infection of the aneurysm found at surgery. The skin over the aneurysm was usually thinned, and sometimes ischemic and eroded.

All the aneurysms appeared at surgery to be true aneurysms located on the venous side of the AV fistula, involving the vein around and up to the anastomotic site (Figures 1a and 2). However, two patients were found to have pseudoaneurysms on histological assessment. All patients in the study were found to have had a previous side-to-side AV anastomosis.

One patient had a dilated, friable brachial artery. He sustained an injury to the site of proximal control of the brachial artery and developed a pseudoaneurysm at that site postoperatively. Another patient developed thrombosis of

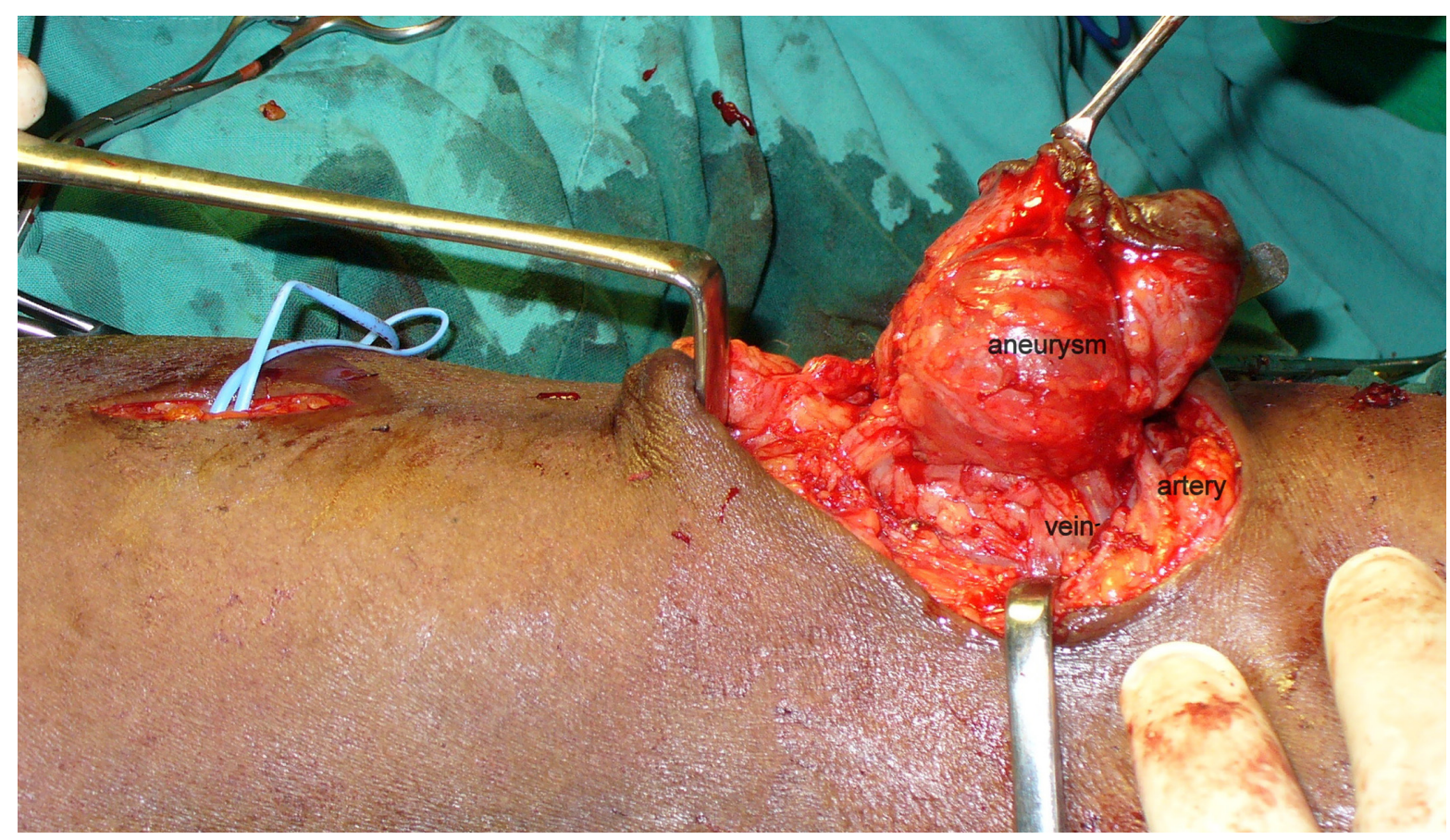

Figure 2 The AV fistula aneurysm at surgery. Figure demonstrates the relationship of the artery, vein and the aneurysm as seen at surgery. 
the artery less than 24 hours after surgery and was treated effectively by embolectomy.

Duration of post-surgical followup was variable. At the time of data collection, two patients had died of causes unrelated to their surgical procedure; one at three years and one at two months after surgery. The durations of followup for the remaining patients were $18,16,11,6$ and 4 months.

\section{Discussion}

This series, albeit small, is probably representative of the experience of a small surgical unit lacking a dedicated vascular service. Our hospital provides a hemodialysis service to 122 patients per week, with dialysis procedures being performed by trained nursing staff.

Aneurysm formation is one of the complications of the use of AV fistulae for hemodialysis, with a reported incidence of $5 \%$ to $6 \%$. ${ }^{1}$ These are generally a mixture of true and pseudoaneurysms, and occur as a result of the puncture techniques used. ${ }^{2,3,5}$ Early intervention is advised in the treatment of these patients. ${ }^{4}$ This reduces the risk of complications, especially rupture. As noted earlier, two of our patients presented with rupture.

Excision of the aneurysm and the communicating veins with restoration of continuity of the artery has been described. ${ }^{2}$ However, this technique leaves the patient without a functional fistula. In 2003 Pierce et $\mathrm{al}^{4}$ demonstrated preservation of the AV fistula in such patients by stapling across the aneurysm sac. In the same year Lo and $\operatorname{Tan}^{1}$ described plicating the excess wall of the aneurysmal sac, again preserving the fistula. This resulted in a delay in the time interval until the fistula could be used ranging from three weeks to 30 days. Although our attempts at fistula preservation involved excision of the excess aneurysmal wall, we believe the overall result would have been similar to that achieved by the above researchers. However, the AV fistulae were lost in the patients in whom we attempted to preserve it. In the later patients in our series, for whom new AV fistulae were created, the fistulae were patent and usable.

Arterial blood flow increases progressively in the first 10 days after fistula formation and then tapers off, ${ }^{5}$ so it should

Open Access Surgery

\section{Publish your work in this journal}

Open Access Surgery is an international, peer-reviewed, open access journal that focuses on all aspects of surgical procedures and interventions. Patient care around the peri-operative period and patient outcomes post surgery are key topics. All grades of surgery from minor cosmetic interventions to major surgical procedures are covered. Novel techniques Submit your manuscript here: http://www.dovepress.com/open-access-surgery-journal be possible to start use of the fistula at this time. We therefore anticipate that there would be a more rapid return to use of a fistula with the surgical method we describe. Unfortunately, the delay time to use was longer in our patients because of the historical practice of waiting four weeks before fistula use.

Other methods described for dealing with these cases include endovascular stenting, perivascular mesh, and thrombin injection. ${ }^{6-8}$ However none of these options were available for our patients.

\section{Conclusion}

AV fistulae aneurysms can be effectively treated by excision of the aneurysmal sac and repair of the artery followed by creation of a new AV fistula at the same sitting via the same incision. This can theoretically result in a delay time to fistula use of only 10 days. This would also save patients having to have a second surgical procedure for creation of an AV fistula.

\section{Disclosure}

The authors report no conflicts of interest in this work.

\section{References}

1. Lo HY, Tan SG. Arteriovenous fistula aneurysm - plicate, not ligate. Ann Acad Med Singapore. 2007;36(10):851-853.

2. Karabay O, Yetkin U, Silistreli E, Uskent H, Onol H, Açikel U. Surgical management of giant aneurysms complicating arteriovenous fistulae. J Int Med Res. 2004;32(2):214-217.

3. Wang A, Silberzweig JE. Brachial artery pseudoaneurysms caused by inadvertent hemodialysis access needle punctures. Am J Kidney Dis. 2009;53(2):351-354.

4. Pierce GE, Thomas JH, Fenton JR. Novel repair of venous aneurysms secondary to arteriovenous dialysis fistulae. Vasc Endovascular Surg. 2007;41(1):55-60.

5. Konner K, Nonnast-Daniel B, Ritz E. The arteriovenous fistula. $J$ Am Soc Nephrol. 2003;14(6):1669-1680.

6. Grauhan O, Zurbrugg HR, Hetzer R. Management of anuerysmal arteriovenous fistual by a perivascular metal mesh. Eur JVasc Endovasc Surg. 2001;21(3):274-275.

7. Padberg FT, Calligaro KD, Sidawy AN. Complications of arteriovenous hemodialysisaccess: Recognition and management. J Vasc Surg. 2008;48(5S):55S-80S.

8. Corso R, Rampoldi A, Vercelli R, Leni D, Vanzulli A. Percutaneous repair of radial artery pseudoaneurysm in a hemodialysis patient using sonographically guided thrombin injection. Cardiovasc Intervent Radiol. 2006;29(1):130-132.

and the utilization of new instruments and materials, including implants and prostheses that optimize outcomes constitute major areas of interest. The manuscript management system is completely online and includes a very quick and fair peer-review system. Visit http://www.dovepress.com/ testimonials.php to read real quotes from published authors. 